\title{
Meeting complexity with collaboration: a proposed conceptual framework for participatory community-based music therapy research in end of life-care
}

\author{
Wolfgang Schmid \\ The Grieg Academy, Department of Music, Faculty of Fine Art, Music and Design, University of Bergen; Sunniva Centre for Palliative \\ Care, Haraldsplass Deaconess Hospital, Bergen, Norway
}

\begin{abstract}
Research in end-of-life care is complex with specific ethical and practical challenges related to epistemology, methodology and recruitment of people approaching the end of life. However, to ensure the provision of high-quality care research efforts need to be aligned with the priorities of patients, their families, and interdisciplinary team members. A more systematic engagement of all three groups in research is needed to promote tailored and appropriate end-of-life care. In this methodological article I propose a conceptual framework for community-based participatory music therapy research in end-of-life care scenarios as one promising strategy to respond to ethical and practical challenges, to handle complexity and advance integration of perspectives. The conceptual framework consists of two thematic clusters i) Participlinarity across contexts, and ii) Community-based participatory music therapy research in end-of-life care scenarios. Though in the early stages of development, the framework addresses issues of educational strategies and continuity of care, and aims to contribute to innovative music therapy research in the future.
\end{abstract}

\section{Introduction}

Music therapy in multidisciplinary end-of-life care dates back to the 1970s. It is highly accepted by people approaching the end of life and beset with few side ef-

Correspondence: Wolfgang Schmid, The Grieg Academy, Department of Music, Faculty of Fine Art, Music and Design, University of Bergen, Lars Hilles gt 3, 5015 Bergen, Norway.

Tel.: +47.45200271

E-mail: wolfgang.schmid@uib.no

Acknowledgments: the author would like to thank an anonymous reviewer for valuable comments on an earlier version of the manuscript and Felicity Burbidge Rinde for text-editing.

Key words: Music therapy; End-of-life-care scenarios; Participatory research; Participlinarity.

Conflict of interest: the author declares no potential conflict of interest.

Funding: the literature search for this article was partially funded by POLYFON - Knowledge Cluster for Music Therapy, University of Bergen, Norway.

Received for publication: 27 September 2018.

Revision received: 28 November 2018.

Accepted for publication: 28 November 2018.

This work is licensed under a Creative Commons Attribution NonCommercial 4.0 License (CC BY-NC 4.0).

C Copyright W. Schmid, 2018

Licensee PAGEPress, Italy

Qualitative Research in Medicine \& Healthcare 2018; 2:145-153

doi:10.4081/qrmh.2018.7850 fects. ${ }^{1}$ Nowadays both music therapy practice and research have been implemented internationally. ${ }^{2}$ A recently published integrative review on music therapy in end-oflife care found 1629 research studies on the subject, conducted between 1978 and 2016. ${ }^{2}$ There is increasing evidence of music therapy's benefits in end-of-life care with an overall tendency to psycho-physiological improvement. However, these improvements are captured and expressed quite contrasting by patients and healthcare providers. While the latter ones focus on the measurement of symptoms like pain and anxiety, patients and their families themselves associate music therapy rather with the promotion of well-being and the improvement or completion of relationships. On the background of these diverging perspectives, an integrative, participatory design for future music therapy research is recommended. ${ }^{2}$ In general, research in end-of-life care is complex, and researchers and participants face specific ethical and practical challenges. These challenges include i) recruitment and involvement of terminally ill people presenting with often frail and rapidly changing conditions in research, ii) strategies for the identification of research topics and outcomes relevant for the people involved, and iii) an increasing preference for end-of-life care at home. ${ }^{3,4}$ These issues are true for any discipline conducting research with people in end-of-life care - music therapy included. Moreover is research most often conducted solely from one perspective, that means from the one of healthcare professionals, or family members and/or terminally ill people themselves. ${ }^{2,5}$ This one-sidedness is clearly in contrast to the WHO definition of palliative care, highlighting more holistic approaches and multidisciplinary mindsets to improve terminally ill people's quality of life. ${ }^{6}$ 
A more systematic engagement of all three groups in research is seen to support tailored and appropriate care at the end of life. ${ }^{7}$ Consequently, research efforts need to be aligned with the priorities of patients, their families, and interdisciplinary team members. ${ }^{5}$

In 2012 the Norwegian Ministry of Health and Care stated that a more active role of patients in the development of innovative future healthcare services is as important as professionals' and politicians' contributions. ${ }^{8}$ Accordingly, patient's knowledge and experience needs to be weighted equally with specialist knowledge to promote co-engagement and innovation in healthcare services and research. This co-engagement can inform new forms of collaboration in working life and education, a change of existing cultures and attitudes in communication, and new strategies to support decision making processes.

On this background, I focus in this article on the development of a conceptual framework for participatory research in music therapy within the field of end-of-life care and the idea to meet the complexities specific to research in end-of-life care with collaboration. I have been stimulated and informed by literature on participatory research in end-of-life care, ${ }^{7,9-12}$ music therapy research and theory, as well as by a recently published integrative review on the diverging perspectives of patients and healthcare providers on music therapy in end-of-life care. ${ }^{2}$ In the following, I will develop two thematic clusters in a synthesis of the aforementioned sources. The two clusters form the conceptual framework and address questions of who is part of the research community, and how a participatory research approach does respond to ethical and practical challenges specific to end-of-life care scenarios. I introduce the term end-of-life care scenarios here to account for the dynamic, unique and often multi-layered, changing and unpredictable aspects, including interactions of people, places and cultural aspects at the end of life.

In the following, I will present key principles of both community-based participatory research and music ther- apy as an ecological practice in end-of-life care scenarios. Thereby I establish a theoretical and epistemiological basis for the proposed conceptual framework.

\section{Community-based participatory research in healthcare}

Community-based participatory research is a form of social inquiry involving all participants actively in all aspects of the research process, which has recently been extended to use in health and social care. ${ }^{9,10}$ Examples of participatory research include action research, cooperative inquiry, and community-based participatory research, to name but a few. ${ }^{7,11,12}$ Despite differences among these approaches, all draw upon constructivist and critical theoretical perspectives and have three core values: i) participation: addressing collaboration in the research process in order to empower people, practitioners, and researchers; ii) action: bringing about change for people, organizations, and systems; iii) reflection: generating knowledge through collective reflective processes. ${ }^{7}$ Israel et al. ${ }^{12}$ have formulated key principles for community-based participatory research in healthcare (Table 1). ${ }^{7,12}$

Following the constructivist paradigm, in participatory research multiple socially constructed realities that are influenced by social, cultural, and historical contexts exist. A fundamental characteristic of community-based participatory research is the emphasis on the participation and influence of non-academic researchers in the process of creating knowledge. It is not research on people, nor is it research for people, but research with people. ${ }^{13}$ Participatory research adopts a way of how we view the world (ontology) that accommodates multiple perspectives, commits to action within the research process, and is based on inclusiveness and relationship building. ${ }^{14}$ To get at the tacit and common-sense knowledge that comes from experience and underpins practice, researchers build relationships with practitioners and engage with them as co-researchers. Knowledge is generated from the experi-

Table 1. Key principles of community-based participatory research in healthcare contexts. ${ }^{12}$

Community-based participatory research in healthcare

1. Recognizes a community as a unit of identity

2. Builds on strengths and resources within a community

3. Facilitates a collaborative and equitable partnership in all phases of the research

4. Fosters co-learning and capacity building among all partners

5. Balances knowledge and action for mutual benefit of all partners

6. Promotes an empowering process that attends to social inequalities

7. Addresses locally relevant health problems and considers multiple determinants of health and disease

8. Occurs in a cyclical and iterative process that includes ongoing evaluation of successes and obstacles

9. Disseminates findings and knowledge gained to all partners

10. Involves a long-term process and commitment to sustainability 
ence of living and learning (epistemology). Its creation involves social processes and is subject to others' interpretation and critique. Specific research methods are determined collaboratively by the purpose of the study, the context and setting, the theoretical perspectives (including local theory), and the input of community participants. ${ }^{12}$ Thus, a continual dialectic of iteration, analysis, assessment, reiteration, and reanalysis integrates knowledge gained with actions to improve health in the communities involved. An enhanced understanding of a given phenomenon in health and social care research becomes possible. Rather than being simply a research method, participatory research is an approach to research that emphasizes the intentional engagement of community members in sharing their unique perspectives and local knowledge throughout the research process - from problem definition through data collection and analysis to the dissemination and use of findings - to help effect change. ${ }^{7,11,12}$ While there is extensive research into symptom control and experiences of different aspects of end-of-life care, actually researching day-to-day practice within specialist palliative care using participatory approaches is much less common. ${ }^{9}$ This is curious, as existing community-based participatory research is highly suited to the ethical and practical challenges associated with end-of-life care research and has been found to hold substantial potential for advancing current opinions of the field and promoting sensitivity for future programs, practices and policies. ${ }^{7}$ However, it can be a demanding process when multiple ways of knowing and investigation meet, interact, and develop an understanding of each other. ${ }^{11,15}$ While a purposeful inclusion of multiple perspectives is seen as a strength of community-based participatory research, more time is required to reach common understandings (or close to common understandings) in the heterogeneous group specific to this kind of research. ${ }^{16}$ Westhues et al. ${ }^{16}$ conclude that to achieve a synthesizing analysis of multiple perspectives and data sources within their collaborative mixed method participatory action research study required considerable reflection and ongoing dialogue. They emphasize the importance of strong project management skills to coordinate the many meetings and decisions required in the research process and to engage all partners in a meaningful way, particularly when it comes to data analysis and theory building. For some partners the process of theory development might be too abstract, whereas the presentation of results might well benefit from non-academic perspectives and ways of doing things. Furthermore, Westhus et al. ${ }^{16}$ recommend that the allocation of roles is clear and transparent from the very start of a participatory research project. ${ }^{10}$ Stable long-term working relationships of academic and non-academic partners have also been found to give non-academic researchers greater comfort and confidence to express their opinions, and see themselves as full members of the research team. ${ }^{16}$

\section{Music therapy as an ecological practice in end-of-life care scenarios}

An ecological perspective in healthcare encompasses context in the broadest sense of the word. It includes physical, social, cultural, and historical aspects of context as well as attributes and behaviours of the persons within. ${ }^{17}$ Movements such as ecological, community and social psychology have increasingly used an ecological metaphor. ${ }^{17}$ Music therapy as an ecological practice focuses on the promotion of health within and between various layers of the socio-cultural community and/or physical environment. ${ }^{18}$ Also included are any efforts to form, build, or sustain communities through music therapy. Hereby music emerges between and amongst people: Making music is making social life. Thinking about music in this way is to take a broadly ecological perspective, exploring how people thrive and sicken, adapt and develop in relation to their ever-changing physical, social and cultural environment. ${ }^{19}$ Such approaches include next to a person presenting with health issues his/her family, workplace, community, society, or physical environment, either because the health of the ecological unit itself is at risk and therefore in need of intervention, or because the unit in some way causes or contributes to the health problems of its members. ${ }^{18}$ Consequently, all people involved contribute with their abilites and disabilities, their history and inherited culture, their personal preferences, talents, habits of action and practice, thoughts and memories..$^{20}$ Due to this interdependendence of agents and layers, the basic premise of music therapy as an ecological practice is that change in one will ultimately lead to changes in the other. Health and well-being are not viewed as an individual enterprise separate from improving the health of the ecological context within which the individual lives. ${ }^{18}$ Within the last decades, these ideas have been captured particularly in the community music-, and community music therapymovement. ${ }^{18,19}$ As an ecological practice, music therapy follows where music's natural tendencies lead: both inwards in terms of its unique effects on individuals, but also outwards towards participation and connection in communitas. ${ }^{19}$ To that end, a variety of music therapeutic approaches and settings are at disposal, ranging from individual music therapy in a therapy room or at the bedside of a person to group-driven singing or listening activities including family, healthcare staff or community members. Common to all these approaches and settings is the way in which music's capabilities unfold as a part of a broader ecology of people, places and cultural practices, and can locate and develop what is still healthy in a person or a situation, despite illness or deprivation. ${ }^{19}$ To follow a person's social and musical needs in this way opens up for a ripple effect addressing the where and with whom music therapy can take place. In a pilot study on community music therapy in a neuro-rehabilitation unit, the music therapist Wood ${ }^{21}$ developed a Matrix model based on an understanding that the essence of any form of music mak- 
ing is the way in which music works within and between people. This includes individual music therapy in acute and in-patient settings, group music therapy in community medical settings, arts workshops, and concerts in community venues. All these different formats of music therapy create opportunities to follow people throughout their individual progression in rehabilitation. In the same way can music therapy be adapted to various end-of-life care scenarios. To meet the complex and changing needs of a person presenting with terminal illness as well as of the other people involved, the flexibility and permeability of music therapy as suggested in the Matrix model ${ }^{21}$ is crucial. Thus, music therapists accompany terminally ill over extended periods of time as well as in the very last hours of life. Music therapy takes place in people's homes or in institutions like hospices or a home for the elderly. Music therapists take also part in funerals and accompany bereaved people in their grieving processes.

Music therapy as an ecological practice acknowledges and embraces the complexity of end-of-life care scenarios in a diverse ways and modes dependent on the people, places, and actions involved. Moreover, it responds to a community's spiritual and transcendental needs. ${ }^{19}$ Thereby does music not work like a medication that leads to change in itself, but therapeutic meaning and change do unfold in the relationships forming and being formed by the people making music or listening to it in a certain context. ${ }^{19}$ In a participatory action research single-case study ${ }^{22}$ a couple where one of the partners was affected by amyotrophic lateral sclerosis, a neurodegenerative disease, developed and implemented home-based music therapy based on their musical preferences. They chose music listening as their favourite method, using the music streaming program Spotify, as well as YouTube. Over the course of twelve weeks, the couple together with the music therapist created a musical atmosphere in the sessions in which both positive and challenging emotions could be expressed and shared. At the same time, ways of coping evolved and the couple could access own competencies and resources in a situation mostly determined by degeneration and loss. This led to a shift of focus towards the experience of regaining control, improved quality of life, and a strengthening of the couple's own relationship and their relationship with the music therapist. Music therapy as an ecological practice includes an awareness of context, with music therapy in and as context, as well as music therapy as interacting contexts. ${ }^{23}$ As in the example with the couple who developed their own madeto-measure music therapy, the musical activities are taking place in context, with reference to an awareness of the surroundings of music therapy. In the case of the couple this was within the intimacy of the their own home. At the same time, music therapy served as context for the couple and the music therapist, pointing to the ecology of reciprocal influences within the sessions and their relationships with each other. And thirdly the ripple effect, connecting participants of music therapy to a wider community, refers to music therapy as interacting contexts, inviting an awareness of the ecology of reciprocal influences between various systems that music therapy is part of and relates to. ${ }^{23}$

As a potential strategy for how these essentials of music therapy practice can be transferred into music therapy research, I present in the following a conceptual framework for the implementation of community-based participatory music therapy research in end-of-life care scenarios consisting of two thematic clusters. I develop the clusters in a synthesis of the aforementioned specific challenges for research in end-of-life care scenarious, peculiarities of community-based participatory approaches as well as music therapy as ecological practice in end-of-life care scenarios. The clusters are thematically interwoven, overlap and refer to each other: i) Participlinarity Across Contexts (PAC): who forms the research community, suggesting participlinarity as the equal co-engagement of academics and non-academics with their diverse knowledge and competences? ii) Music therapy as an Ecological practice in end-of-life Care Scenarios (MECS): how does a community-based participatory music therapy research approach respond to ethical and practical challenges specific to end-of-life care scenarios?

\section{Participlinarity across contexts (PAC) - cluster I addressing the who?}

Interdisciplinary collaboration and a more active role for users have been emphazied for the development of future healthcare services. ${ }^{5,7}$ To frame and implement this more comprehensively, the thematic cluster PAC captures questions concerning definition of membership, level and scope of involvement, and responsibility in communitybased participatory music therapy research at the end of life. The key principles of both, community-based participatory research (Table 1), and music therapy as an ecological practice (Table 2) are woven into the formation of this cluster. I suggest the term participlinarity to capture peculiarities of the question who are deemed members in a participatory research project, and who defines this. With participlinarity I mean more than simply people with terminal illness, family members or lay carers joining academics and healthcare professionals collaboratively in a research project. Rather is participlinarity a mutual, performed and collaborative activity within a broader community of people, forming a partnership approach to research in healthcare. ${ }^{24}$ I emphasize with the term participlinarity a co-engagement of academics and non-academics sharing a concern, a set of problems, or a passion about a topic. All partners involved acknowledge and equally value the others' different ways of knowing. This forms the very basis for negotiation and decision-making processes and has the potential to lead to synergies and innovations beyond what one partner can achieve alone. In this way participatory community-based research may positively address effective communication around end-of-life 
issues being a critical aspect of current patient care and medical practice. ${ }^{11}$ To further illuminate the idea of participlinarity as presented here, I consider the theory of learning by Wenger-Trayer et al. ${ }^{25}$ as relevant. Wenger-Trayer's theory is founded on the assumption that engagement in social practice is the fundamental process by which we learn and so become who we are. People generate knowledge in diverse ways, from different sources and for different purposes. They engage in actions and negotiate meanings with one another in communities of practice. A community of practice is a group of people who share a concern, a set of problems, or a passion about a topic, and who deepen their knowledge and expertise in this area by interacting on an ongoing basis. ${ }^{25}$ Within these communities of practice, bodies of knowledge evolve that are capable for the inclusion and integration of a diversity of competencies, values, ideals, realities and ways of knowing. Pivotal to community-based participatory research (Table 1) and learning as social practice alike is an epistemological understanding of knowledge that is generated from the experience of living and learning, involving social processes. Thus, all members of a community have the competence to contribute a wide spectrum of knowledge, and act, react and interact with each other. Such processes are enactive in nature, and emphasize the very doing of collaboration as a determining characteristic of participlinarity. In this way lived experience and academic ways of gaining knowledge can be shared on an equal footing between all partners on an ongoing basis. Music therapy as an ecological practice (Table 2) can serve as context for participlinary research processes, and connect participants in and across contexts. A music therapist can follow a person approaching the end of his/her life and his/her community of practice across contexts, and in accordance with the needs arising. The contexts can be linked through music, and the music therapist can bridge transitions from one context to the other, promoting continuity of care. At the same time, more comprehensive music therapy research can be conducted, integrating perspectives of all community partners on what music therapy can specifically do in various end-of-life care scenarios. Mutual engagement, a joint enterprise and a shared repertoire stimulate the activities of the members of the community. ${ }^{25}$
Furthermore, each member's experience is shaped in a process of transformation, and at the same time shapes the practice of the community. In this way, co-learning and innovative capacity building are facilitated among all partners. The joint enterprise ${ }^{25}$ reflects the full complexity of mutual engagement and is the participants' negotiated response to their situation. It belongs to them in a profound sense. Transferring Wenger-Trayer's ideas to communitybased participatory music therapy research in end-of-life care, the definition of outcomes, the research process, and the findings are the community's response to the situation. In music therapy people mutually engage with each other, musical pieces represent their jont enterprise and shared repertoire. They are their musical response to their situation. Thus, multiple determinants of health and disease, including institutional and home-based conditions as well as locally relevant problems concerning end-of-life care are addressed. In this way participatory community-based music therapy research is research with people. ${ }^{13}$ They themselves care for each other, their well-being, ideas and needs. Naturally will partners in a participatory research project own and further develop modes of communication on an equal basis. They will develop a shared repertoire of ways of doing things, stories, styles, or concepts. ${ }^{25}$ Specifically, they will develop a shared repertoire of songs and musical pieces in music therapy, as well as ways of sharing and performing them. In a cyclical and iterative process that includes ongoing evaluation of successes and obstacles, modes of communication between partners will be developed. This, in turn, may serve as a strategy to nurture long-term processes, sustainability and dissemination of findings and knowledge gained to all partners (Table 1). The shared repertoire may refer to the heterogeneity of the group, while at the same time it forms a unique body of knowledge dependent on the end-of-life care scenario. Hence, participlinarity means that membership in a participatory research project is determined by the fact that firstly, one is affected by end-of-life care, either as a person experiencing terminal illness, or as a relative, friend, specialized nurse, physiotherapist or researcher. And secondly, membership is hallmarked through an openness and readiness of each member, to deepen knowledge and expertise by interacting with others on an ongoing basis.

Table 2. Key principles of music therapy as an ecological practice in end-of-life care scenarios.

\section{Music therapy as an ecological practice}

1. Recognizes and promotes the involvement of particular people and their particular relationships with families, friends and within a wider community

2. Takes place in particular settings: at people's homes, a hospice or a community venue

3. Takes place at particular times: an appointed therapy session, or a more spontaneous music making including family members or nurses

4. Uses particluar things: musical instruments and equipment, a location, a stage

5. Promotes the performance of who people still are

6. Accounts for a community's transcendental and spiritual needs 


\section{Community-based participatory music therapy research in end-of-life care scenarios (MECS) cluster II addressing the how?}

The second thematic cluster MECS addresses how a participatory approach to music therapy research might help to i) facilitate recruitment and involvement of terminally ill people presenting with often frail and rapidly changing conditions, ii) strategies for the identification of research topics and outcomes relevant for these people, and iii) an increasing preference for end-of-life care at home.

\section{Facilitation of recruitment and involvement of terminally ill people in music therapy research}

People with terminal illness may struggle with very real practical challenges such as pain, anxiety, restlessness, poor concentration and limited attention span. ${ }^{26}$ Their condition can change rapidly which in turn can impact recruitment and resources for participation over several weeks. ${ }^{26}$ In addition, relatives and carers may try to protect a person approaching the end of life from the perceived burden of being involved in research by not giving consent or by thwarting their participation in other ways. ${ }^{7}$ A participatory community-based research approach has been found to potentially overcome some of the barriers to recruitment and also to promote long-term commitment by inviting community members to select a topic that is relevant to their specific needs. ${ }^{3}$ With respect to music therapy research, a community with its particular members will be invited to explore and implement their music at particular places and times, forming a community of music over time (Table 2). The members will explore their needs and resources expressed in and through music within the context of music therapy. All members will be actively involved from the very beginning of a research project. Such involvement of persons with lived experiences is increasingly viewed as key for the improvement and utility of health research and service innovation. The World Health Organisation and several countries have developed legislation strengthening patients influence, giving them greater control over the services offered. ${ }^{27}$ Their perspectives have been widely acknowledged as being important for the definition of outcome measures as well as for casting light on mechanisms of therapeutic change. ${ }^{28}$ The involvement of people with lived experiences is associated with positive clinical outcomes, such as improved self-esteem and confidence, as well as therapeutic benefits resulting from increased social interaction and coordination of care. ${ }^{29}$ Furthermore, funding institutions increasingly require research professions to state how they intend to involve people whose lives are implicated in the research project. ${ }^{15}$ As a consequence, established research epistemology and the relationships between researchers and researched are questioned: Who defines criteria for participation, scope and level of involvement $?^{11,15}$ In particular, there has been debate over whether it is ethical to include or exclude terminally ill people as participants in a research study. ${ }^{5,7}$ People approaching the end of their life may be seen to be too vulnerable to allow for valid and generalizable research. The population is heterogeneous with limited time for involvement, and the participants will not have the opportunity to benefit from the results of the research. ${ }^{30}$ On the other hand, not offering terminally ill people the opportunity to participate in research negates their right to have their voices heard. ${ }^{16}$ While these individuals are unlikely to benefit directly from the knowledge generated by the research they are involved in, they may nevertheless experience subjective benefits from their participation. Hopkinson et al. ${ }^{3}$ found in their participatory research that people with advanced cancer were not as overwhelmed by their participation as expected, but in fact welcomed the opportunity to contribute to finding solutions for others facing terminal illness. Gysel et al. ${ }^{5}$ found in their review on views and experiences in research at the end of life that the majority of patients were willing to take part in research, with their families supporting this. Also hospice staff and hospice organizations were found to have positive attitudes towards research participation. Accordingly, do researchers need to co-engage with patients and their families, and design and implement projects collaboratively.

\section{Strategies for the identification of research topics and outcomes relevant for all people involved}

Community-based participatory research begins with a topic of importance to the community. ${ }^{7}$ The methods used are collaboratively tailored to the purpose of the research and the context and interests of the community. The direct involvement of all members in decision-making processes ensures that the research methods become consistent with the needs and services delivered to people approaching the end of life and their families. In concrete can music therapy as an ecological practice serve as the very place for people to express their needs and resources and thereby inform the determinantion of topics and outcomes relevant for research. In the example with the couple where one of the partners was affected by amyotrophic lateral sclerosis, they themselves developed and implemented home-based music therapy practice as well as relevant questions for subsequent research. ${ }^{22}$ The identification of research topics and outcomes pertinent for the people involved develops out of practice and feeds into a community-based participatory research design. In this sense, are music therapy practice and research not separate processes, but interdependent. Research is practice-led and research questions will emerge, that might challenge conventional topics, measurement tools and questionnaires used so far. Drawing upon community wisdom and ensuring that the research topic reflects a major issue identified by the community is seen as crucial for the improvement of the quality, validity and sensitivity of participatory approaches. ${ }^{7}$ However, this requires a great willingness on the part of members to disclose their personal views of the situation, their own opinions and experiences. To support the members, a safe space is needed. ${ }^{11}$ 
In everyday life, openness about personal opinions is generally displayed towards family or close friends. This can be more difficult in institutional settings or with strangers. The fear of saying something wrong may prevent people from expressing their real views and opinions, especially when these opinions appear to contradict what others think. However, participatory research specifically seeks these dissenting views: They are essential to the process of knowledge production since they promise a new take on the subject under study, thereby enabling the discovery of new aspects of the topic. Therefore, the research contract needs to be negotiated continually, including the boundaries of the communicative space, the type of participation and leadership expected, opportunities to express concerns and anxiety, and balance between order and chaos. ${ }^{11}$ Music therapy as an ecological practice can provide a save space where particularities of all members, their individual abilities, dsiabilites, histories, resources, personal preferences, habits of action and practice can unfold (Table 2). Moreover, established roles and hierarchies are challengend and changed in music therapy. The music therapist Aasgaard investigated the environmental impact of music therapy on the milieu of an oncological pediatric ward. ${ }^{31}$ One of his findings was, that doctors and nurses involved in music therapy sessions with the children and their families changed their established roles. In turn, to see the authorities becoming absorbed in some artistic or musical activity, helped to humanise the impression that patients and relatives have of those in power at the hospital, and the spirit of community was strengthened within the institution. ${ }^{31}$

Community members may also be involved in the development of research instruments, as well as being trained as interviewers. The involvement of all project members in the process of writing and publishing has been suggested as a way to obtain more in-depth discussions, reflection and increased understanding of the overall process of conducting participatory research. ${ }^{32}$ Consequently, a triangulation of multiple sources of data, methods, and investigators is specific for participatory research. ${ }^{11,15}$ Both academic and non-academic members can be involved as co-authors in a writing team, respond to initial manuscript drafts, data analysis and interpretations. With respect to the dissemination of findings of music therapy research, this might have the format of a documentary report of a therapeutic process or the performance of a song composed by community members. In this sense might community-based music therapy research also stimulate new ways of dissemination of findings. This may help to improve the translation of findings into policy and practice, and enhance the uptake of the research findings by other communities. ${ }^{7}$

\section{Music therapy research across settings: responding to an increasing preference for end-of-life care at home}

End-of-life care scenarios take place in both institutional and home-based settings with a variety of profes- sional and lay carers involved. ${ }^{33}$ Through the changing conditions of a person with terminal illness, a change of setting in the course of the caring process - from home to hospital, or from hospital to a home for the elderly or a hospice - is most likely. As populations age, more and more people have indicated a preference for end-of-life care at home. In addition, policy makers have identified home care as cost-effective, shifting the care of patients from hospital to home. ${ }^{4,33}$ Though demographic and social trends highlight the necessity to strive for quality end-oflife home care, home and (in-patient) hospice settings create different focuses for professionals and interdisciplinary team members, burdens and privileges for family caregivers, and control of the care plan. ${ }^{33}$ While interdisciplinary collaboration in people's homes results in higher satisfaction, fewer clinic visits, fewer symptoms and overall improved health for patients, family caregivers need strengthening of their competences. ${ }^{34}$ The inclusion of family caregivers in music therapy has been highlighted as one specific beneficial feature of homebased music therapy. ${ }^{4}$ Their competencies are strengthened and it opens up for new ways of family activities and quality time with each other. ${ }^{22}$ The ideas presented in the cluster PAC and the ripple effect of music therapy activities allow for a direct inclusion of family members in music therapy, as well as a transfer and continuation of services across contexts. Music therapy as an ecological practice can meet people wherever they are, adapt to a change of settings and accompany transfers from one context to another. This will inform and stimulate the implementation of participatory music therapy research across contexts. However, more research needs to be conducted with respect to the inclusion of family caregivers. This will promote the investigation of how such changes and transitions take place, what questions and challenges arise within the communities of practice, and how these can be met and answered.

In the last section of this article, I will briefly discuss the two clusters PAC and MECS with respect to consequences for future music therapy research. Specifically, potential implications for educational strategies in researcher-training and for the facilitation of continuity of care across end-of-life care scenarios will be considered.

\section{Discussion}

Many of the challenges and benefits of participatory music therapy research mentioned in this article relate to wider societal, economic, institutional, or cultural issues going beyond the discipline itself. They question established traditional views, roles, hierarchies and expectations present in current healthcare systems and research more in general. However, on a system's level, there is growing awareness for the importance of the involvement of patients, that means of people with lived experiences of illness. Nevertheless, the actual implementation, trans- 
lating the rhetoric of empowerment and participation into practice, is lagging behind. ${ }^{8}$ In particular, patients have found it difficult to have real impact on decision making processes across all levels of health care services. Their involvement is dependent on the extent of cooperation and assistance they actually get. ${ }^{35}$ Against this background, I propose with the two thematic clusters PAC and MECS potential strategies for a more systematic inclusion of people approaching the end of life in communities of practice with co-engagement and impact throughout all phases of a music therapy research project. The clusters are uniquely situated to address a range of methodological, ethical and practical challenges in music therapy research. They may help to identify innovative topics for future projects, relevant to all members of a research community. Ethical and practical challenges are present in participatory research too, and there is a need for great awareness of these throughout any project. However, these challenges can be handled in various ways in the cases in question, as the research is participatory in nature and follows the premises of persons with terminal illness and their families. Moreover, educational strategies are advised to researchers conducting community-based participatory research, as the high level of skill and responsibility required calls for training in both research processes and ethics. ${ }^{12}$ The emergent nature of social relationships with communities means that ongoing evaluation and researcher self-reflection are crucial. ${ }^{36}$ Training and education is essential at all levels - for researchers, ethics committee members, administrators, and community participants. Furthermore, Israel et al. ${ }^{12}$ suggest, that curriculum in healthcare education covers the knowledge and skills necessary for professionals to be able to conduct participatory research. Ethical challenges will not be entirely resolved but training and education are likely to lessen their scope. ${ }^{36}$

A unique pecularity of community-based participatory music therapy research is to account for continuity of care. Both thematic clusters illustrate the potentials for this in manifold ways. Continuity of care is considered patients and professionals alike to be an essential feature of highquality healthcare. ${ }^{37}$ Biringer et al. ${ }^{37}$ explored peoples' experiences and perceptions of continuity of care within mental healthcare. They developed five themes along continuums from poor to good experiences of continuity of care: Relationship - from experiencing frequent setbacks and anxiety due to breaks in relationships, to feeling safe in an ongoing personal relationship; Timeliness - from experiencing frustrating waiting times with worsening of problems, to getting help when needed; Mutuality - from having a one-sided struggle, to a situation in which both professionals and service users take initiative; Choice from not having the opportunity to make practical arrangements within the context of one's everyday life, to having an array of support options to choose from; Knowledge from feeling confused and insecure due to not knowing what is happening, to feeling safe thanks to clear information about what is going to happen. The presentation of the themes on a continuum of good and bad experiences with continuity of care holds a mirror up to the challenges and opportunities of music therapy research in end-of-life care scenarios as presented in this article. It is therefore vital to turn attention to the importance of relationships, mutuality and co-enagegement, shared knowledge, timing of treatment and choice-making, in order to implement inclusion and participlinarity in future music therapy research. In this way may the conceptual framework I propose in this article serve as a theoretical basis to further promote the implementation of participatory music therapy research projects in end-of-life care scenarios.

\section{Conclusions}

In this methodological article I developed a conceptual framework for community-based participatory music therapy research in end-of-life care scenarios. From my perspective as a music therapy practitioner and researcher, this is one promising strategy and response to ethical and practical challenges, handling complexity and advancing integration of perspectives. Though music therapy practice and research are part of present healthcare systems, I do not suggest any generalizations for research in the area of end of life beyond the scope of this framework. The framework may first of all promote comprehensive and integrative future music therapy research, and also facilitate further investigation of what music therapy can do in end-of-life care scenarios. Certainly, the framework is in the early stages of development. A next stage will comprise its incorporation into specific music therapy research projects. Meeting complexity with collaboration across contexts will contribute to further development and modification of the framework.

\section{References}

1. Archie P, Bruera E, Cohen L. Music-based interventions in palliative cancer care: a review of quantitative studies and neurobiological literature. Support Care Cancer 2013;21: 2609-24.

2. Schmid W, Rosland JH, von Hofacker S, et al. Patient's and health care provider's perspectives on music therapy in palliative care - an integrative review. BMC Palliat Care 2018;17:32.

3. Hopkinson JB, Wright DN, Corner JL. Seeking new methodology for palliative care research: challenging assumptions about studying people who are approaching the end of life. Palliat Med 2004;19:532-7.

4. Schmid W, Ostermann T. Home-based music therapy - a systematic overview of settings and conditions for an innovative service in healthcare. BMC Health Serv Res 2010; 10:291.

5. Gysels MH, Evans C, Higginson IJ. Patient, caregiver, health professional and researcher views and experiences of 
participating in research at the end of life: a critical interpretive synthesis of the literature. BMC Med Res Methodol 2012;12:123.

6. World Health Organization (WHO). WHO definition of palliative care. Available from: http://www.who.int/cancer/palliative/definition/en/ Accessed: 13.08.2018.

7. Riffin C, Kenien C, Ghesquiere A, et al. Community-based participatory research: understanding a promising approach to addressing knowledge gaps in palliative care. Ann Palliat Med 2016;5:218-24.

8. God kvalitet - trygge tjenester - Kvalitet og pasientsikkerhet i helse- og omsorgstjenesten Available from: https:// www.regjeringen.no/no/dokumenter/meld-st-10-20122013/ id709025 Accessed: 10.08.2018.

9. Hockley J, Froggatt K, Heimerl K. Participatory research in palliative care. Actions and reflections. Oxford: Oxford University Press; 2013

10. Belone L, Lucero JE, Duran B, et al. Community-based participatory research conceptual model: community partner consultation and face validity. Qual Health Res 2014; 26:117-35.

11. Bergold J, Thomas S. Participatory research methods: a methodological approach in motion. Qual Soc Res 2012;13. Available from: http://www.qualitative-research.net/index. php/fqs/article/view/1801/3334

12. Israel BA, Schulz AJ, Parker EA, et al. Review of community-based research: assessing partnership approaches to improve public health. Ann Rev Public Health 1998;19:173-202.

13. Reason $P$, Bradbury H. Introduction: inquiry and participation in search of a world worthy of human aspiration. In: Reason P, Bradbury H, eds. Handbook of action research: participative inquiry and practice. London: Sage Publications; 2001. pp 1-14.

14. McNiff J, Whitehead J. All you need to know about action research. London: Sage; 2006.

15. Feiring M, Knutsen IR, Juritzen TI, Larsen K. Kritiske perspektiver i helsefagene: Utdanning, yrkespraksis og forskning. Cappelen Damm Akademisk; 2017.

16. Westhues A, Ochocka J, Jacobson N, et al. Developing theory from complexity: Reflections on a collaborative mixed methods participatory action research study. Qual Health Res 2008;18:707-17.

17. McLaren L, Hawe P. Ecological perspectives in health research. J Epidemiol Commun Health 2005;59:6-14.

18. Bruscia K. Defining music therapy. Dallas: Barcelona Publishers LLC; 2014.

19. Ansdell G. How music helps in music therapy and everyday life. Dorchester: Ashgate Publishers; 2015.

20. DeNora, T. Music in everyday life. Cambridge: Cambridge University Press; 2000.

21. Wood S. "The Matrix": A model of community music therapy processes. Voices: A World Forum for Music Therapy 2006;6.

22. Schmid W, Ek Knutsen MS. Musikk som helseresurs i hverdagen for hjemmeboende pasienter. In: Stige, B, Ridder HM, eds. Musikkterapi og eldrehelse. Oslo: Universitetsforlaget; 2016. pp 79-87.

23. Rolvsjord R, Stige B. Concepts of context in music therapy. Nord J Music Ther 2015;24:44-66.

24. Stige B. Health musicking: a perspective on music and health as action and performance. In: MacDonald R, Kreutz G, Mitchell L, eds. Music, health, and wellbeing. Oxford: Oxford University Press; 2010. pp 183-195.

25. Wenger-Trayer E, Fenton-O'Creevy M, Hutchinson S, et al. Learning in landscapes of practice: boundaries, identity, and knowledgeability in practice-based learning. London-New York: Routledge; 2015.

26. Warth M, Kessler J, Hillecke TK, Bardenheuer HJ. Music therapy in palliative care. Deutsches Arzteblatt Int 2015;112:788-94.

27. Omeni E, Barnes M, MacDonald D, et al. Service user involvement: impact and participation: a survey of service user and staff perspectives. BMC Health Serv Res 2014;14:491.

28. Vahdat S, Hamzehgardeshi L, Hessam S, Hamzehgardeshi Z. Patient involvement in health care decision making: a review. Iran Red Crescent Med J 2014;16:12454.

29. Wohleber AM, McKitrick DS, Davis SE. Designing research with hospice and palliative care populations. Am J Hospice Palliat Med 2012;29:335-45.

30. Wright DN, Hopkinson JB, Corner JL, Foster C. How to involve cancer patients at the end of life as co-researchers. Palliat Med 2006;20:821-7.

31. Aasgaard T. Music therapy as milieu in the hospice and paediatric oncology ward. In: Aldridge D, ed. Music therapy in palliative care. New voices. London: Jessica Kingsley Publishers; 2000. pp 29-42.

32. Clarke CL, Wilkinson H, Watson J, et al. A seat around the table: participatory data analysis with people living with dementia. Qual Health Res 2018;28:1421-33.

33. Lysaght HS, Barg FK, Strumpf N, Ersek M. Same agency, different teams. Perspectives from home and inpatient hospice care. Qual Health Res 2014;25:923-31.

34. Reinhard SC, Given B, Petlick NH, Bemis A. Supporting family caregivers in providing care. In: Hughes RG, ed. Patient safety and quality: an evidence-based handbook for nurses. Rockville (MD): Agency for Healthcare Research and Quality (US); 2008.

35. Storm M, Hausken K, Knudsen K. Inpatient service providers' perspectives on service user involvement in Norwegian mental health centres. Int J Social Psychiatry 2011;57:551-63.

36. Wilson E, Kenny A, Dickson-Swift V. Ethical challenges in community-based participatory research: A scoping review. Qual Health Res 2017;28:189-99.

37. Biringer E, Hartveit M, Sundför B, et al. Continuity of care as experienced by mental health service users - a qualitative study. BMC Health Serv Res 2017;17:763. 